\title{
Gérard de Nerval, histoire et politique
}

Fabienne Bercegol

\section{(2) OpenEdition}

\section{Journals}

Édition électronique

URL : https://journals.openedition.org/studifrancesi/22966

DOI : 10.4000/studifrancesi.22966

ISSN : 2427-5856

Éditeur

Rosenberg \& Sellier

\section{Édition imprimée}

Date de publication : 1 avril 2020

Pagination : 199

ISSN : 0039-2944

\section{Référence électronique}

Fabienne Bercegol, « Gérard de Nerval, histoire et politique », Studi Francesi [En ligne], 190 (LXIV | I) |

2020, mis en ligne le 01 mai 2020, consulté le 03 août 2021. URL : http://journals.openedition.org/ studifrancesi/22966 ; DOI : https://doi.org/10.4000/studifrancesi.22966

\section{Ce document a été généré automatiquement le 3 août 2021.}

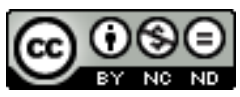

Studi Francesi è distribuita con Licenza Creative Commons Attribuzione - Non commerciale - Non opere derivate 4.0 Internazionale. 


\title{
Gérard de Nerval, histoire et politique
}

\author{
Fabienne Bercegol
}

\section{RÉFÉRENCE}

Gérard de Nerval, histoire et politique, dir. Gabrielle CHAMARAT-MALANDAIN, Jean-Nicolas ILLOUZ, Mireille LABOURET, Bertrand MARCHAL, Henri SCEPI et Gisèle SÉGINGER, Paris, Classiques Garnier, 2018, 434 pp.

1 Se situant dans le prolongement des études qui ont montré l'ancrage de l'œuvre nervalienne dans l'Histoire, les vingt et un articles réunis dans ce volume s'intéressent plus particulièrement à la dimension politique de ces textes que Nerval lui-même invite à comprendre comme une attitude d'opposition. Ce sont les déclinaisons des réactions à l'actualité historique et aux événements du passé ainsi que leurs répercussions sur la poétique nervalienne, sur sa mélancolie diffuse, sur ses soubassements mythiques, qu'explore cet ouvrage organisé en cinq parties.

2 La première, intitulée «Fragments d'un discours sur l'Histoire», caractérise l'écriture discontinue de l'Histoire que pratique Nerval en faisant ressortir sa dette à l'égard des Idéologues (Adriana CHIMU HARLEY, pp. 33-47), de Nodier (Emmanuel BURON, pp. 49-67) et du romantisme allemand (Dagma WIESER, pp. 69-81). Tous ces articles se rejoignent dans le constat que Nerval se distingue par sa sensibilité plus grande aux germes de renaissance que contiennent les ruines du passé (Patrick LABARTHE, pp. 21-32), marqué par la mort des religions, et par son pari sur le triomphe de l'imagination et sur l'efficace de l'utopie.

3 La deuxième partie consacrée aux «Questions d'Orient» doit son unité au parti de délaisser la dimension fictionnelle du récit de voyage pour examiner la réaction du voyageur à la réalité orientale, à ses mœurs, à sa situation politique (Philippe DESTRUEL, pp.111-127), dont il se révèle un fin observateur, moins prisonnier que d'autres des préjugés occidentaux. En se fondant sur ses relations avec les femmes esclaves du Caire, Kan NOZAKI (pp. 85-98) commence du reste par établir en quoi Nerval se différencie du discours orientaliste contemporain, ce qui explique qu'il ait été épargné par les 
critiques d'Edward Saïd. Sarga MousSA (pp. 99-110) nous dépeint un voyageur dépité de retrouver en Orient les modes bourgeoises qu'il croyait avoir fuies et que les réformes à l'européenne des sultans ont à ses yeux le tort d'importer. Cet Orient trop ressemblant a néanmoins le mérite de réaliser l'idéal syncrétiste nervalien par la cohabitation de la «croix» et du «croissant» qu'il parvient à ménager (Henri BONNET, pp. 129-140).

La troisième partie nous ramène en France pour montrer comment la «mélancolie» et la «fantaisie», inspirée notamment de Sterne (Marta KAWANO, pp. 161-174), qui irriguent tour à tour le récit nervalien sont au service d'une lecture critique du présent. Filip KEKUS (pp. 143-159) revient fort à propos sur le journaliste qu'a été Nerval et redonne toute leur importance aux chroniques publiées dans la petite presse satirique, où s'exprime un point de vue malicieux sur l'actualité et où s'invente une écriture de la facétie et de la dérision dont les œuvres postérieures hériteront. C'est à une stimulante traversée de cette œuvre que nous invite Gabrielle CHAMARAT-MALANDAIN (pp. 175-188): passant en revue les différentes façons d'y inscrire l'actualité, elle note son intériorisation croissante dans des récits qui s'en font l'écho à travers le prisme de l'autobiographie et du rêve. Jean-Nicolas ILLouz (pp. 189-207) se centre pour sa part sur Les Faux Saulniers pour illustrer à son tour la présence d'une véritable pensée de l'Histoire, et notamment de ses phénomènes de «revenance», au sein d'un récit intime travaillé par la veine excentrique.

5 En s'employant à cerner l'attitude de Nerval face aux «révolutions et utopies», la quatrième partie permet de dégager les lignes de force d'une conception de l'Histoire qui ne se coupe jamais de l'actualité, qui reste fidèle aux valeurs du «libéralisme moral et philosophique» (p. 220), mais qui s'exprime de préférence par le détour du mythe et par la composition de galeries de figures de rebelles incarnant une continuité de la révolte et permettant de revenir sur le souvenir de 1789 (Keiko TsujIKAWA, pp. 231-243). Gisèle SÉGINGER (pp. 211-230) et Françoise sYLVos (pp. 257-276) livrent une analyse toute en nuances des formes de la contestation chez cet auteur que l'on ne saurait considérer comme «dépolitiqué», selon le mot de Baudelaire, y compris dans les textes les plus autobiographiques, comme le prouve Michel BRIX, en traquant les manifestations de ses «préoccupations démocratiques et républicaines» (pp. 245-255).

6 Si les choix d'écriture de Nerval n'ont jamais été négligés jusque-là dans l'analyse de ses orientations politiques, ce sont plus spécifiquement sur les genres littéraires qu'il a privilégiés que porte la dernière partie («L'Histoire polygraphe»): les contributeurs s'attachent à montrer comment Nerval s'est approprié l'élégie nationale (Pierre LOUBIER, pp. 279-293), l'odelette (Hisashi mizuno, pp. 295-314), le roman de la Révolution (JeanMarie Roulin, pp. 315-329), le drame (Jean-Pierre мітсноviтсн, pp.331-346) et plus généralement, comment les lieux investis par son théatre sont le support d'une véritable géopolitique (Sylvain LEDDA, pp. 347-360).

7 Complété par une enquête de Jean-Marc VASSEUR sur l'histoire du Valois, et notamment de l'abbaye de Chaalis (pp.361-404), ce volume bien construit que l'on referme sur l'émouvante reproduction de la dernière communication prononcée par Jacques BONY (pp. 405-414), répond pleinement au projet de montrer comment, d'un bout à l'autre de l'œuvre de Nerval, se manifeste «une contestation globale dont la politique n'est qu'un aspect» (p. 267) et qui s'accomplit en une métaphysique de l'Histoire dont le mythe est le principal vecteur. 